\title{
EFFECT OF APPLIED TREATMENTS ON GROWTH PERFORMANCE OF THREE CULTIVATED MEDICINAL PLANTS OF KASKI DISTRICT, NEPAL
}

\author{
Y. P. Timilsina (Nepal) \\ H. P. Tripathee (Nepal)
}

\begin{abstract}
This research explores the growth performance of three potential medicinal plants namely, Bajradanti (Potentilla flugens), Chutro (Breberisaristata), and Timur (Xanthoxylumarmatum) cultivated at nursery of Institute of Forestry with the application of tunnel, shaded and open beds treatment each with $4.0 \mathrm{~m} \times 1.0 \mathrm{~m}$ size and constant supportive facilities of manure, irrigation and care. From the measurement of ten months growth performance, B. Aristata and X. armatum showed their better growth in open bed than shed and tunnel beds, unlike P. Flugens showed better performance in shed bed. The average growth performances per month of P. fulgens and X. armatum vary significantly with respect to applied treatments $(p<0.05)$ but converse in the case of $B$. aristatawhen using parametric F- test based on one way analysis of variance. Determined contribution of open treatment for growth performance per month in the species indicates that natural climate is tolerable as well as favorable for thorny types of medicinal plants than that of others.
\end{abstract}

KEYWORDS: Potentilla fulgens, Breberisaristata, Xanthoxylumarmatum, cultivation, growth, F-test

\section{INTRODUCTION}

National and global demands of herbal medicine are accelerating every year (Karki, 2005). In parallel, uncontrolled exploitative practices and lack of concerted conservation efforts, now threaten the country's medicinal plants (Singh et al., 1979; Olsen et al., 2003). Medicinal plants are used in order to relieve, prevent or cure the disease or to alter physiological and pathological process and are also employed as a source of drugs or their precursors. Medicinal plants also play an important role in the lives of rural people particularly in remote parts of developing countries including Nepal where only few health facilities are provided by government (Prajapati and Purohit, 2003). Nepal represents one of the world's richest pockets of biodiversity. The plant resources are the most precious wealth of the country, which provide wide range of useful products such as food, medicine, timber, fuel wood, fiber etc. Indigenous knowledge on the use of plant resources is deeply rooted in the tradition and culture of Nepalese people. Among different plant resources of the country, Medicinal and Aromatic Plants (MAPs) 
have been considered as one of the most precise and important Non Timber Forest Products (NTFPs) contributing to the national economy (Olsen and Helle, 1997). These plants have also become one of the important sources of medicine for the local healers in the villages as well as the basic raw materials for Ayurvedic, Tibetean, homeopathic and allopathic medicines (Gewali, 2008).

Nepal, the Himalayan nation is covering an area of 1,47,181 sq. km has globally significant and biologically diverse ecosystems. It has all the climate zones of the globe representing alpine to tropical in different physiographic zones. This unique geography of Nepal has made it rich in biological resources having valuable non-timber forest products (NTFPs) including medicinal and aromatic plants (MAPs), comprising about $10 \%$ of the vascular plant species (Malla and Shakya, 1984).

Nepal is ranked as 9th among the Asian countries for its floral wealth. (Bhattarai, et al, 2011). In Nepal, 6,653 species of flowering plants have been reported among these, about $50 \%$ fall under the ethnobotanical and about $25 \%-50 \%$ are ethnomedicinal (Kunwar et al., 2010). Catalogues have recorded 1,792 (Rokaya et al. 2010) to 2,331 (Baral et.al 2006) useful medicinal and aromatic plants in Nepal, reporting their importance in alleviating human suffering because they have long been used for subsistence, home remedies, and traditional therapies.

Kaski District lies in Western Development Region of Nepal having altitudinal ranges from around $800-7000 \mathrm{~m}$ is the home of large number of low to high altitudinal MAPs including, Potentilla fulgens, Breberisaristata,Xanthoxylumar matum and others. These MAPs have great potential both for the local health treatment and income generation of rural people. The potential three MAPs have their ethnomedicinal values. According to Kaul et al. (2011), the juice of P. flugens is used as stomach problems, cough and cold, root powder is used toothache, stomach disorders, and anthelmintic, fresh root is used as cough and cold, diarrhoea, diabetes, mellitus cancer and for strengthening gums, root juice is used as tooth infections, root paste is used as peptic ulcer and disusia masticated for pyorrhea and leaves and whole part is used as respiratory complaints. Similarly, fruits of B. aristata are edible and used for making alcohol. The stem and root boiled with water and taken to cure eye infection, fever and headache. Singh et al. (2011) mentioned that fruit decoction of X. armatum, is used for abdominal pain, berries are carminative, antispasmodic and used for rheumatism and skin diseases, barks are used for diabetes, cholera and asthma, pickles from the fruits are useful for cold and cough, tonsillitis, headache, fever, high altitude sickness, limbs numbness, vertigo/dizziness, diarrhoea and dysentery. Powered dried fruits are taken with hot water to cure diarrhoea, dysentery, stomachache.

A large number of people in rural areas of Nepal still depend upon such potential herbal medicine for their basic health care. There is still lack of scientific investigation on many of those medicinal plants of the country. This study intended to explore and identify valuable medicinal plants in regard to their ethnomedicinal importance and evaluation of the effect of applied treatments on growth performance of three cultivated medicinal plants at Nursery as well as initiation of research and development in the academic institutions like Institute 
of Forestry, Pokhara, Nepal.

\section{METHODS AND MATERIALS}

\section{General Site Survey and Species Selection}

All the potential forests for MAPs were identified through official records of District Forest Office (DFO), Kaski district. Reconnaissance survey was carried out in forests to identify potential MAPs with the help of forest user groups (FUGs). In addition, participatory resource mapping was also prepared to select potential forests containing high value MAPs. From these tools, three forests were selected for the study of high potential MAPs. The selected forests include both community and governmental forests. Focus group discussion and key informant interview were also arranged to identify three traditionally and commercially potential MAPs. Based upon these surveys, one MAP species was selected from each forest. Seedlings of Bajradanti (P. fulgens) from Panchase forest of Bhadaure-Tamagi Village Development Committee (VDC), Chutro (B. aristata) from Paripakha Community Forest (CF) of Sardikhola VDC and the already prepared seedling of Timur (X. armatum) by the people of the area of Khara of Sardikhola VDC of Kaski district were taken.

\section{Establishment of Nursery and Cultivation of MAPs}

A nursery is established inside IOF for cultivation and growth performance study of selected MAPs. A hut is also built up to conduct nursery work smoothly. One plastic tunnel bed, three roofed (shed) beds and three open beds were prepared in the nursery for the comparative study of the growth performance of MAPs. The size of bed were $4.0 \mathrm{~m} \times 1.0 \mathrm{~m}=4 \mathrm{sqm}$. Facility of water tank of the size $2 \times 2 \times 2$ cubic meters at the height of 5 feet above the ground connected to high density polythene pipe was laid to each nursery bed. For the establishment of nursery beds, the loamy soil was made by mixing $40 \%$ sand, $40 \%$ silt and $20 \%$ clay (Brady, 2000). Organic manure was also managed together with the loamy soil for the beds. The cultivation of seedlings of three selected MAPs was made in a loamy soil and added necessary manures in the beds of nursery. Nursery care taker was appointed to facilitate the activities related to the nursery such as weeding, watering and other care.

\section{Measurement of MAPs at Nursery}

After cultivation of MAPs at nursery, initial measurement was conducted. This measurement was done every month for ten months. Other constant treatments such as irrigation, addition of fertilizer, weeding and cleaning were done in same day for all treatment applied beds to minimize the influence of systematic error. The height of MAPs was measured from part outside soil (plane bed level/ bottom) to its top. Difference of succeeding height to preceding height was taken as the monthly growth of that species.

\section{Data Analysis and Interpretation}

Quantitative data were analyzed using descriptive statistics (frequency, 
diagram, graphs, average, standard error, maximum, minimum,) with the help of SPSS and MS Excel. Inferential statistics based on parametric F-test which is concerned with one way analysis of variance (ANOVA) was used to test hypothesis whether there is significance difference or not in the average growth performance per month of each species with respect to applied treatments as open, shed and tunnel.

\section{RESULTS AND DISCUSSION}

\section{Status of Initial Numbers of Cultivated Maps Seedlings}

All three selected MAPs were cultivated and treated by three treatments via. open, shed and tunnel with the sufficient replications as well as supplied of equal amount of manure so that all the other factors are taken as constant to minimize experimental error. Maximum attempts were made to minimize systematic error in the case of cultivation as well as measurement time.

Table 1: Two way table showing the number of seedlings of medicinal plants at nursery with respect to applied treatments

\begin{tabular}{|l|l|l|l|l|}
\hline \multirow{2}{*}{$\begin{array}{c}\text { Applied treat- } \\
\text { ments }\end{array}$} & \multicolumn{2}{|c|}{ No. of cultivated medicinal plant seedlings } & \multirow{2}{*}{ Total } \\
\cline { 2 - 4 } & $\begin{array}{c}\text { Bajradanti } \\
(\mathbf{P} \text { fulgens) }\end{array}$ & $\begin{array}{c}\text { Chutro } \\
(\text { B. } \text { aristata })\end{array}$ & $\begin{array}{c}\text { Timur } \\
(\text { X. } \text { armatum })\end{array}$ & \\
\hline Open & $24(35.29)^{\star}$ & $5(35.71)$ & $11(32.15)$ & $40(34.48)$ \\
\hline Shed & $24(35.29)$ & $5(35.71)$ & $10(29.41)$ & $39(33.62)$ \\
\hline Tunnel & $20(29.41)$ & $4(28.57)$ & $13(38.24)$ & $37(31.90)$ \\
\hline Total & $68(100)$ & $14(100)$ & $34(100)$ & $116(100)$ \\
\hline
\end{tabular}

${ }^{* *}$ Parentheses in brackets show the percentage within species

Table 1 predicts that overall numbers of species of cultivated P. fulgens has higher in numbers than that of other species due to the easy and sufficient availability as well as easy for hollow out from the area. On the other hand, less collection as well as less cultivation of B. aristata shows the uprooting process is too much laborious as well less possibility of uprooting with root. All MAPs type in nursery with respect to total in each applied treatments are almost the equal in numbers but little bit higher in open. Within species, more P. fulgens and B. aristata were cultivated in same numbers in shed and open. But, in the case of X. armatum, higher numbers are cultivated in tunnel followed by open and shed respectively.

\section{Growth Status of Potential Medicinal Plants with Respect to Applied Treatments}

Different mode of applied treatments in the nursery has played vital role in the growth performance of medicinal plants where the other external factors were kept constants as much as possible except extraneous chance factors i.e. genetic, environmental etc. which are beyond the objective of this research. Growth performance per month (increment of height in $\mathrm{cm}$ ) of each species based on three different treatments was measured at IOF nursery of Pokhara between July, 2012 and May, 2013. 


\section{Growth Status of P. fulgens}

Average growth performances of the P. fulgens vary with respect to applied treatments in the nursery. Average growth per month with standard error, maximum and minimum values as well as lower and upper bound 95\% confidence intervals for average are presented in table 2.

Table 2: Descriptive statistics of the growth $(\mathrm{cm})$ of P. fulgens in nursery

\begin{tabular}{|c|c|c|c|c|c|}
\hline \multirow{3}{*}{$\begin{array}{c}\text { Applied } \\
\text { Treatments }\end{array}$} & \multicolumn{5}{|c|}{ Growth $(\mathrm{cm}) /$ month } \\
\hline & \multirow[t]{2}{*}{ Average \pm SE } & \multicolumn{2}{|c|}{$\begin{array}{c}\text { 95\% Confidence Interval for } \\
\text { Average }\end{array}$} & \multirow[t]{2}{*}{ Minimum } & \multirow[t]{2}{*}{ Maximum } \\
\hline & & Lower & Upper & & \\
\hline Open & $1.68 \pm .205$ & 1.2204 & 2.1516 & .05 & 2.20 \\
\hline Shed & $1.70 \pm .234$ & 1.1695 & 2.2305 & .11 & 2.89 \\
\hline Tunnel & $.62 \pm .094$ & .4109 & .8391 & .08 & 1.00 \\
\hline Pooled & $1.33 \pm .140$ & 1.0497 & 1.6243 & .05 & 2.89 \\
\hline
\end{tabular}

The plant is an erect perennial herb with height of 15-75 cm (Kaul et al., 2011). This range verified the height of this species in nursery which lies within the range in saturated flowering stage.

Almost similar highest average growth performance values has occupied by P. fulgens with the application of shed and open treatments with approximately 2.7 times higher than that of applied tunnel treatment. Maximum range of growth appeared in the shed applied treatment followed by open and tunnel applied treatments, respectively. 95\% Confidence Interval for average growth of this species occupies with lowest intervals in tunnel treatments which is 2.48 and 2.17 times less than that of shed and open treatments respectively.

Even though the average growths of that species are much higher in shed and open applied treatments than that of tunnel from descriptive statistical point of view. From inferential statistics, whether average growths of that species differ significantly or not with respect to applied treatments at $5 \%$ level of significance, a parametric Ftest which is based on one way Analysis of variance (ANOVA) is used.

Total variation is inherent in nature. Total variations in any set of numerical data are due to variation between assignable fixed causes as applied treatments and variation due to within treatments as chance causes. The output of ANOVA with sum of squares, degree of freedoms, mean squares, calculated $\mathrm{F}$ and $\mathrm{p}$ values are presented in table 3 .

Table 3: One way ANOVA for growth performance

\begin{tabular}{|l|l|l|l|l|}
\hline \multicolumn{1}{|c|}{ Sources of variations } & \multicolumn{1}{|c|}{$\begin{array}{c}\text { Sum of } \\
\text { Squares }\end{array}$} & $\begin{array}{c}\text { Degree of } \\
\text { freedom }\end{array}$ & $\begin{array}{c}\text { Mean } \\
\text { Square }\end{array}$ & F value \\
\hline Between treatments & 7.605 & 2 & 3.803 & \\
\hline Within treatments & 9.568 & 27 & .354 & $10.73^{\star}$ \\
\hline Total & 17.173 & 29 & & \\
\hline
\end{tabular}

${ }^{\ngtr}$ Significant $(P<.05)$ 
From parametric $\mathrm{F}$ test based on one way ANOVA showed that there is significant difference i.e. considerable variation in the average growths of that species with respect to applied treatments $(\mathrm{p}<.05)$. This indicates that average growths of at least one pair treatment that differ significantly. To identify that pairs, it was used unplanned multiple comparison with least significance difference (LSD) test as numbers of treatments are less than six. Results of multiple comparisons are presented in the table 4 .

Table 4: Unplanned multiple comparison by LSD test

\begin{tabular}{|l|l|l|l|l|}
\hline \multicolumn{2}{|l|}{ Applied treatments pairs } & \multirow{2}{*}{$\mid$ Mean Difference $\mid$} & \multicolumn{2}{|c|}{$\mathbf{9 5 \%}$ Confidence Interval } \\
\cline { 4 - 5 } \multicolumn{2}{|l}{ Open } & & \multicolumn{1}{|c|}{ Lower } & Upper \\
\hline & Shed & .014 & -.560 & .532 \\
\cline { 2 - 5 } & Tunnel & $1.061^{\star}$ & .515 & 1.607 \\
\hline Tunnel & Shed & $1.075^{\star}$ & -1.621 & -.529 \\
\hline
\end{tabular}

${ }^{*}$ Significant $(P<.05)$

Table 4 depicts that there is significance difference in the average growths of that species between applied treatments as open and tunnel as well as shed and tunnel $(\mathrm{p}<.05)$. Furthermore, 95\% Confidence Interval for the mean excludes zero in lower and upper bounds (having same signs) also indicates that respective average growths of that species vary considerably. In overall, out of treatment means of three pairs, average growths of two applied treatments pairs differ significantly.

\section{Growth Status of X.armatum}

Application of different treatments and growth performance of each species in one month's time interval were recorded and growth varies with respect to applied treatments as well as months. Following table shows the summary statistics of the growths ofX. armatum w.r.t. applied treatments in the IOF nursery.

Table 5: Descriptive Statistics of the growth $(\mathrm{cm})$ of X. armatumin Nursery

\begin{tabular}{|c|c|c|c|c|c|}
\hline \multirow{3}{*}{$\begin{array}{l}\text { Applied } \\
\text { treatments }\end{array}$} & \multicolumn{5}{|c|}{ Growth $(\mathrm{cm}) /$ month } \\
\hline & \multirow[t]{2}{*}{ Average $\pm \mathrm{SE}$} & \multicolumn{2}{|c|}{$\begin{array}{l}\text { 95\% Confidence Inter- } \\
\text { val for average }\end{array}$} & \multirow[t]{2}{*}{ Minimum } & \multirow[t]{2}{*}{ Maximum } \\
\hline & & Lower & Upper & & \\
\hline Open & $7.77 \pm .869$ & 5.80 & 9.74 & 1.15 & 11.10 \\
\hline Shed & $5.16 \pm .657$ & 3.67 & 6.64 & 1.40 & 8.00 \\
\hline Tunnel & $4.81 \pm .779$ & 3.04 & 6.57 & .10 & 8.00 \\
\hline Pooled & $5.91 \pm .496$ & 4.90 & 6.92 & .10 & 11.10 \\
\hline
\end{tabular}

Table 5 showed that average growth of that species has occurred 1.6 and 1.1 times higher in open and shed applied treatments, respectively than that of tunnel applied. But, range value i.e. difference between maximum and minimum average growth are in open, tunnel and shed with 9.96, 7.9 and $6.6 \mathrm{cms}$ respec- 
tively. One of the serious issues in the tunnel case in this research has observed that the growth performance in tunnel is low. 95\% Confidence range for average growths w.r.t. applied treatments in nursery of that species is highest in open treatment with value $3.94 \mathrm{~cm}$ and followed by tunnel $(3.53 \mathrm{~cm})$ and shed $(2.97$ $\mathrm{cm}$ ) treatments, respectively. From descriptive statistical point of view, average growths of this species has appeared different in magnitude but from inferential statistical point of view in testing of hypothesis, it was used F-test based on One way ANOVA to test whether average growths of that species differ significantly or not at 5\% level of significance with respect to applied treatments (Table 6) and identified significance pair treatments by using LSD test procedure (Table 7).

Table 6: One way ANOVA for growth performance (cm) of X. armatum in nursery

\begin{tabular}{|l|l|l|l|l|}
\hline Sources of variation & $\begin{array}{l}\text { Sum of } \\
\text { Squares }\end{array}$ & $\begin{array}{l}\text { Degree of } \\
\text { freedom }\end{array}$ & Mean Square & F value \\
\hline Between treatments & 52.506 & 2 & 26.253 & $4.384^{*}$ \\
\hline Within treatments & 161.689 & 27 & 5.988 & \\
\hline Total & 214.196 & 29 & & \\
\hline
\end{tabular}

${ }^{\ngtr}$ Significant $(P<.05)$

Table 6 demonstrated that there is marked differences in the average growths of the species with respect to three treatments in the nursery $(\mathrm{p}<.05)$ i.e., treatment means of at least one pair differ significantly.

When performed unplanned multiple comparison by using LSD test, out of three treatment mean pairs, only two treatments pairs differ statistically significant.

Table 7: Unplanned multiple Comparisons by LSD test

\begin{tabular}{|l|l|l|l|c|}
\hline \multicolumn{2}{|c|}{ Applied treatments pairs } & \multirow{2}{*}{\begin{tabular}{|}
$\mid$ Mean Dif- \\
ference
\end{tabular}} & \multicolumn{2}{|c|}{ 95\% Confidence Interval } \\
\cline { 4 - 5 } & & Lower & Upper \\
\hline \multirow{2}{*}{ Open } & Shed & $2.61^{*}$ & .369 & 4.860 \\
\cline { 2 - 5 } & Tunnel & $2.96^{*}$ & .719 & 5.210 \\
\hline Shed & Tunnel & .35 & -1.895 & 2.595 \\
\hline
\end{tabular}

${ }^{\star}$ Significant $(P<.05)$

Average growth response of open treatment differ significantly from shed and tunnel treatments $(\mathrm{p}<.05)$. Furthermore, $95 \%$ confidence intervals for means of significance treatment pairs excludes zero between lower and upper bounds (having same sign) is also the indication of significant (Table 7).

\section{Growth Status of B. aristata}

B. aristata which is more tolerable thorny plant is cultivated in nursery with large mature state due to unavailability of seedling stage in field collection time. Different treatments applied and growth performances measured to identify best performance treatment with respect to growth. Ten months intervals growth values of that species were measured and descriptive statistics are presented in table 8 . 
Table 8: Descriptive statistics of growth $(\mathrm{cm})$ of B. aristataw.r.t. applied treatments

\begin{tabular}{|c|c|c|c|c|c|}
\hline \multirow{3}{*}{$\begin{array}{l}\text { Applied } \\
\text { treatments }\end{array}$} & \multicolumn{5}{|c|}{ Growth $(\mathrm{cm}) /$ month } \\
\hline & \multirow[t]{2}{*}{ Average $\pm S E$} & \multicolumn{2}{|c|}{$\begin{array}{c}\text { 95\% Confidence Interval } \\
\text { for Mean }\end{array}$} & \multirow[t]{2}{*}{ Minimum } & \multirow[t]{2}{*}{ Maximum } \\
\hline & & Lower & Upper & & \\
\hline Open & $3.44 \pm .475$ & 2.36 & 4.52 & .03 & 5.50 \\
\hline Shed & $2.33 \pm .327$ & 1.58 & 3.07 & .20 & 4.00 \\
\hline Tunnel & $3.01 \pm .393$ & 2.12 & 3.90 & .40 & 5.30 \\
\hline Pooled & $2.93 \pm .240$ & 2.43 & 3.42 & .03 & 5.50 \\
\hline
\end{tabular}

Table 8 elucidates that descriptive characteristic of the growth status of that species with respect to applied treatments. Average growths of this species in open and tunnel treatments are respectively 1.5 and 1.3 times higher than that of shed treatment with higher ranges of open $(5.5 \mathrm{~cm})$ followed by tunnel $(4.9 \mathrm{~cm})$ and shed $(3.8 \mathrm{~cm})$.

Even some differences were observed in average growths of this species with respect to applied treatments. From inferential statistics based on hypothesis testing, a parametric F-test is used.

Table 9: One way ANOVA for growth performance (cm) of B. aristataw.r.t. applied treatments

\begin{tabular}{|l|l|l|l|l|}
\hline \multicolumn{1}{|c|}{ Sources of variation } & \multicolumn{1}{|c|}{$\begin{array}{c}\text { Sum of } \\
\text { Squares }\end{array}$} & $\begin{array}{c}\text { Degree of } \\
\text { freedom }\end{array}$ & $\begin{array}{c}\text { Mean } \\
\text { Square }\end{array}$ & F value \\
\hline Between treatments & 6.32 & 2 & 3.16 & $1.94^{*}$ \\
\hline Within treatments & 43.92 & 27 & 1.62 & \\
\hline Total & 50.25 & 29 & & \\
\hline
\end{tabular}

${ }^{*}$ Non -significant $(P>.05)$

But when parametric F- test based on ANOVA procedure was performed, there is no any remarkable differences in the average growths of that species with respect to applied treatments $(\mathrm{P}>.05)$ as shown in table 9 . In other word, there are no sufficient evidences to reject the hull hypothesis. All the applied treatments have same contribution on the growth of B. aristata in nursery. This may be due to real causes or may be due to less numbers of replications.

\section{CONCLUSION}

The communities of Khara, Sardikhola and Bhadaure-Tamangi were found very knowledgeable in use of plants for treatment of various ailments in local level. Spiritual belief, economy and limitation of alternative health facilities were cause of continuity of people's dependency on traditional healers. From matrix preference ranking, pair wise ranking and key informant survey, Timur, Chutro and Bajradanti found to be the potential MAPs used by communities of Khara, Sardikhola and Bhadaure-Tamangi VDCs respectively. Seedlings of potential MAPs cultivated in the nursery varied in numbers and initial heights 
with respect to different applied treatments. Cultivation of potential MAPs i.e. B. aristata, and X. armatum at IOF nursery showed that their better growth in open than shed and tunnel beds but shed bed for P. fulgens. Determined contribution of open treatment for growth per month in the species indicates that natural climate is tolerable as well as favorable for these types of MAPs.

\section{ACKNOWLEDGEMENTS}

We would like to express our sincere gratitude to institute of Forestry, specially Dean of IOF Prof. CP Upadhyaya and Dr. KP Devkota, Mr. RP Shrama, Mr. JN Shah and Ms. Basudha Shrestha for their continuous support to conduct this research. We gratefully acknowledge the assistance and collaboration of key respondents of user groups of three forests of Khara, Sardikhola and Bhadaure-Tamangi VDCs, Kaski, Nepal. We acknowledge the University Grant Commission, Sanothimi, Bhaktapur for the financial support to conduct this study as an institutional research grant.

\section{REFERENCES}

Baral, S. R. and Kurmi, P. P. 2006. Compendium of medicinal plants in Nepal. Chabahil, Kathmandu, Nepal: Rachana Sharma publishers

Bhattarai K. R., Maren I. E. and Chaudhary R. P. 2011. Medicinal plant knowledge of the Panchase region in the middle hills of the Nepalese Himalaya, BankoJanakari, 21(2) pp. 31-39.

Brady, N. C. 2000. The nature and properties of soils. 10th edition, Prentice-Hall of India Private Limited, New Delhi-110001. pp. 99.

Gewali, M. B. 2008. Aspects of Traditional Medicine in Nepal. Institute of Natural Medicine, University of Toyama, Japan

Karki, M. 2005. The organic production of medicinal and aromatic plants: a strategy for improved value-addition and marketing of products from the Himalayas. In Proceeding of wise practices and experimental learning in conservation and management of Himalayan medicinal plants. Edited by Thomas YA, Karki M, Gurung K, Parajuli D. Kathmandu, Nepal: Ministry of Forests and Soil Conservation

Kaul, K., Jaitak, V. and Kaul, V. K. 2011. Review on pharmaceutical properties and conservation measures of P. flugens wall. Ex Hook- A medicinal endangered herbs of Higher Himalayas, Indian Journal and Natural Resources, 2(3) pp. 298-330

Kunwar, R. M., Shrestha, K, Dhungana, S.K., Shrestha, P.R. and Shrestha, K.K. 2010. Floral Biodiversity of Nepal: an update. Journal of Natural History $\mathrm{Mu}$ seum, 25: pp. 295-311.

Malla, S. B, Shakya, P. R., Rajbhandari, K. R., Bhattarai, N. K. and Subedi, M. N. 1995. Minor forest products of Nepal: general status and trade. Forest resource information system project (FRISP) paper No. 4, HMGN/FINNIDA

Olsen, C. S. and Helle, F. 1997. Medicinal plants, markets and margins in the Nepal Himalaya: trouble in paradise. Mountain Research and Development, 17 (4)

Olsen, C. S. and Larsen, H. O. 2003. Alpine medicinal plant trade and Himalayan mountain livelihood strategies. The Geographical Journal. 
Prajapati, N. D. and Purohit, S. S. 2003. Agro's Colour Atlas of Medicinal Plants, Agrobios,. ISBN 81-7754-172-2.

Rokaya, M. B., Munzbergova, Z, Shrestha, M.R., Timsina, B. 2010. Ethnobotanical study of medicinal plants from the Humla district of western Nepal. $J$ Ethnopharmacol.

Singh, M. P., Malla, S. B., Rajbhandary, S. B., Manandhar. 1979. Medicinal plants of Nepal - retrospects and prospects. Economic Botany

Singh, T. B. and Singh, O.M. 2011. Phytochemical and pharmacological profile of Zanthoxylumarmatum-DC - An overview, Indian Journal and Natural Resources 2(3), pp 275-85

\section{ABOUT THE AUTHORS}

Y. P. Timilsina is the Associate Professor of Statsitics at the Institute of Forestry He has been teaching Experimental Design for Forestry, Research Methodology for Forestey, Statistical Methods and Data Management in under graduate and graduate levels in this institute from the last twenty two years. He has long experience about qualitative and quantitative data analysis and management. He has conducted dozen of trainings of the statistical Packages for Social Sciences (SPSS) for the students and faculty to strengthen the capacity building of data analysis and interpretation. He has supervised and co-supervised four dozens of biophysical and social research theses of under gradute and gradute students at this Institite. He has also experience in field survey of biophysical and social data collection procedures in various geographical regions of Nepal. He has published about one and half dozen research articles in reputed national journals and about half dozen research articles in international peer reviewed journals.Email: timiyp@yahoo.com

H.P. Tripathee is the Associate Professor of Chemistry at the Institute of Forestry with teaching experience of thirty one years. He has supervised and co-supervised research theses of under gradute and gradute students at this Institite. He has also conducted lab based reseaches based on various medicinal plants and fodders of different physiographic regions of Nepal. He has published course book of chemistry and some research articles in reputed national journals. 